\title{
IGF-1-PI3K-Akt-mTOR and Myostatin-SMAD3 Pathways Signaling for Muscle Hypertophy
}

\author{
Mateus 0 Leite $^{1}$, Thales M A Silva ${ }^{1}$ and Marco Machado ${ }^{1,2 *}$ \\ ${ }^{1}$ Universidade Iguaçu Campus V at Itaperuna, Brazil \\ ${ }^{2}$ Fundação Universitária de Itaperuna, Brazil
}

Submission: October 16, 2021; Published: November 19, 2021

*Corresponding author: Marco Machado, Universidade Iguaçu Campus V at Itaperuna, BR356, Km02, Itaperuna, RJ, Brazil

\begin{abstract}
The control of muscle mass depends mainly on the action of two signaling pathways: IGF-1 axis and Myostatin. While one (IGF-1) signals increases in protein synthesis, the other (myostatin) acts by inhibiting muscle growth. The interaction of these signaling pathways with other mechanisms determines muscle mass. Furthermore, an important player in the process are the satellite cells in a dependente or non-dependent way to hypertrophy process.
\end{abstract}

Keywords: Skeletal muscle; Muscle mass control; Muscle protein syntesis

\section{Introduction}

Its described that the size of skeletal muscle is dependent upon the kinetic processes of muscle protein synthesis (MPS) and muscle protein breakdown (MPB), the difference between which (MPS minus MPB) dictates net protein balance [1,2]. A positive protein balance (when MPS is greater than MPB) determines the increase in skeletal muscle fiber volume called hypertrophy. In recent decades, studies in molecular biology and biochemistry have shown two intracellular pathways to control the size of muscle fibers [3-5]. The first of them positively regulates muscle growth, comprising a cascade that includes the growth factor IGF-1. The second pathway is an inhibitory mechanism. It down regulate muscle growth and includes myostatin [3-7]. The purpose of this work is to show that the signaling for muscle hypertrophy is done via activation or not of satellite cells.

\section{Discussion}

It has been showed that the inactivation of IGF-1 in the skeletal muscle of animals impairs growth and reduces the number and size of muscle fibers. On the other side, an overexpression of IGF-1 promotes muscle hypertrophy, in a process dependent on the activation of the PI3K-Akt-mTOR cascade [8-10]. Akt phosphorylation is able to increase protein synthesis, through the activation of mTOR, which interacts with other proteins, to form complexes mTORC1 with a raptor subunit and mTORC2 with a rictor subunit $[10,11]$ (Figure 1).
Amino acids are capable of activating mTOR $[4,12]$. The effect of amino acids in the regulation of protein synthesis seems to be mediated mainly by leucine, through a mechanism that can be via insulin or not. It is important to highlight that although amino acids are fundamental as a substrate for protein synthesis, the simple increase in intake does not induce hypertrophy per se [13]. Based upon animal and cell culture studies, only leucine is required to induce protein synthesis and mTOR signaling, however, in vivo human studies are needed to validate this hypothesis [14].

Knock-out animals for mTOR, present reduced postnatal muscle growth and expressive reduction in size only of the fast-twitch fibers with preservation of the slow ones despite severe myopathy [15]. Despite the activation of two complexes associated with mTOR, complex 1 has a more important role in protein synthesis, being also the target of the inhibitory potential of rapamycin, whose treatment inhibits development, muscle regeneration and compensatory hypertrophy caused in experimental models by eliminating synergists $[11,15]$.

As showed, although mTORC1 is capable of influencing the 4EBP1 (eukaryotic translation initiation factor) and S6K1 (S-6 Kinase 1) factors, only the latter is essential for muscle hypertrophy and, in fact, its deletion it results in atrophy and prevents the anabolic effect of the constitutive activation of Akt $[5,15]$. It has also been shown that the protein AMP kinase (AMPK), activated 
when intracellular energy levels are decreased, is able to block the inducing effect of mTORC1 on muscle hypertrophy and AMPKdeficient mice demonstrate hypertrophy $[16,17]$. Despite this, other factors must be involved in the activation of hypertrophy independently of mTOR activation, as rapamycin is able to only partially inhibit the accumulation of ribosomal RNA necessary for protein synthesis and which normally occurs after activation of mTORC1 in conjunction with the synthesis of tRNA and nuclear RNA polymerases I, II and III [7].

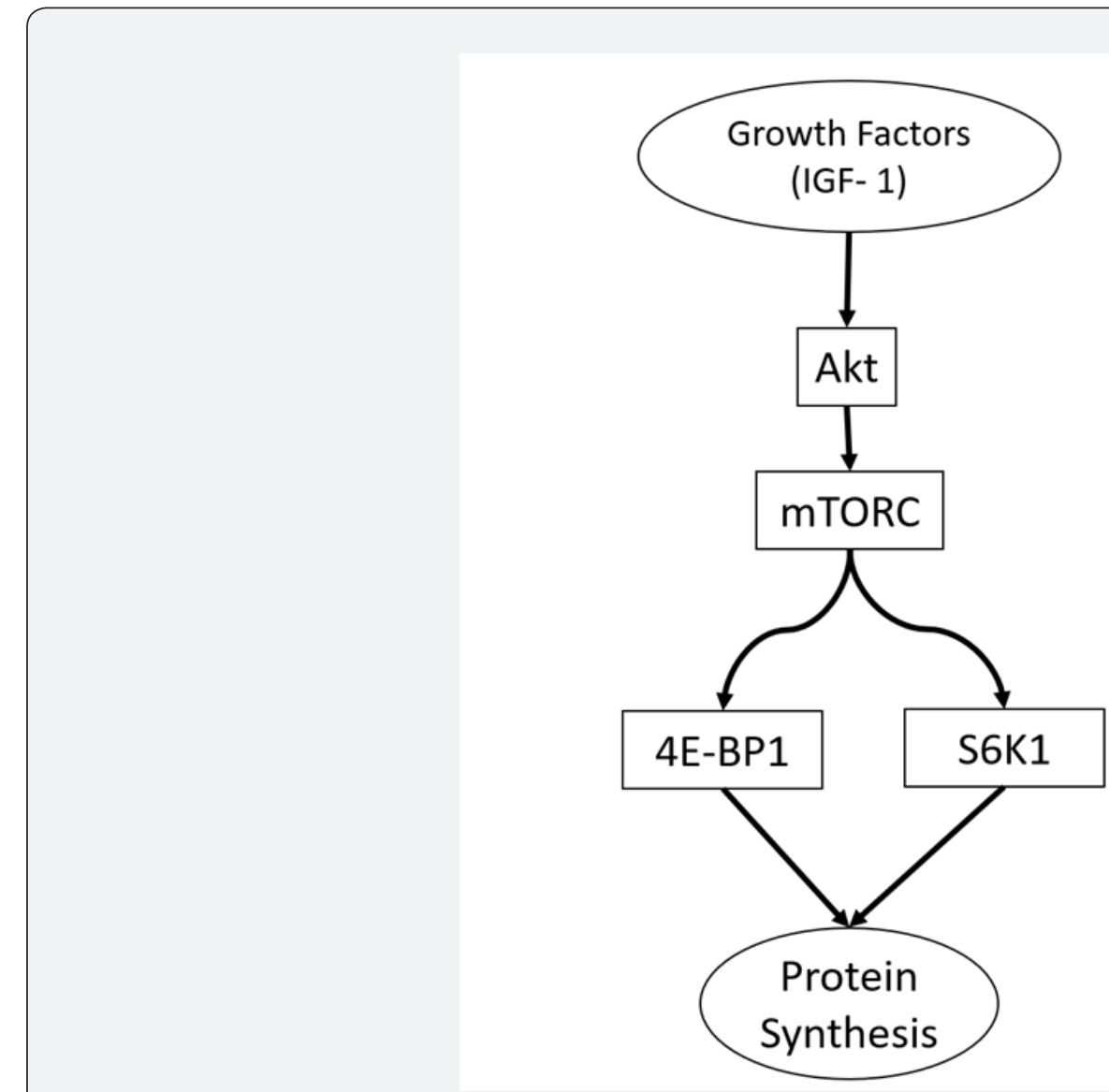

Figure 1: Schematic representation of the IGF-1 pathway.

Interestingly, it was affected that the transcription factor Yin-Yang (YY1) is able to physically interact with mTORC1 and mediate the expression of mTOR-dependent mitochondrial gene expression [7]. Apparently, mTORC1 seems to be able to induce YY1 phosphorylation, inducing the displacement of a transcription repressor complex of several genes that directly contributes to the expression of numerous genes involved in the insulin/IGF-1 signaling pathway, including IGF1, IRS1, IRS2, Akt1 and Akt2 $[7,18]$. In this context, the administration of rapamycin, by inhibiting mTORC1 and dephosphorylating YY1, recruits again the repressor complex of the promoter region of these genes and blocks its transcription [7].

A second muscle hypertrophy control pathway involves a myostatin, a member of the transforming growth factor superfamily (TGF- $\beta$ ). Myostatin is produced by skeletal muscle itself and negatively regulates muscle growth [16]. The exposure of purified myostatin inhibits the protein synthesis of cultured myotube cells and its systemic administration promotes muscle atrophy in mice [16]. The participation of myostatin in this phenomenon has been classically represented by the high levels of hypertrophy observed in several species of mammals that have mutations in the myostatin gene [18] (Figure 2).

A protein known as follistatin has also been identified, which is produced by skeletal muscle and capable of inhibiting the action of myostatin, in addition to binding and neutralizing the activity of activin-A, another member of the TGF- $\beta$ family that it also acts as a negative regulator of muscle growth [19]. Follistatin has a more profound impact on hypertrophy than the myostatin gene deletion itself [20]. Myostatin and activin-A interact with each other and activate heterodimeric receptor in a process that antagonizes protein synthesis and muscle hypertrophy, and which can be inhibited by administering the soluble form of activin-A type II 
receptor (ACVR2B) [19]. The signal mediated by the myostatin/ activin-A complex is believed to occur through phosphorylation and nuclear translocation of transcription factors SMAD2 and
SMAD3 and formation of heterodimers with SMAD4. Although the targets of these factors are not yet known, it is speculated that they interfere negatively in the Akt-mTOR pathway [21,22].

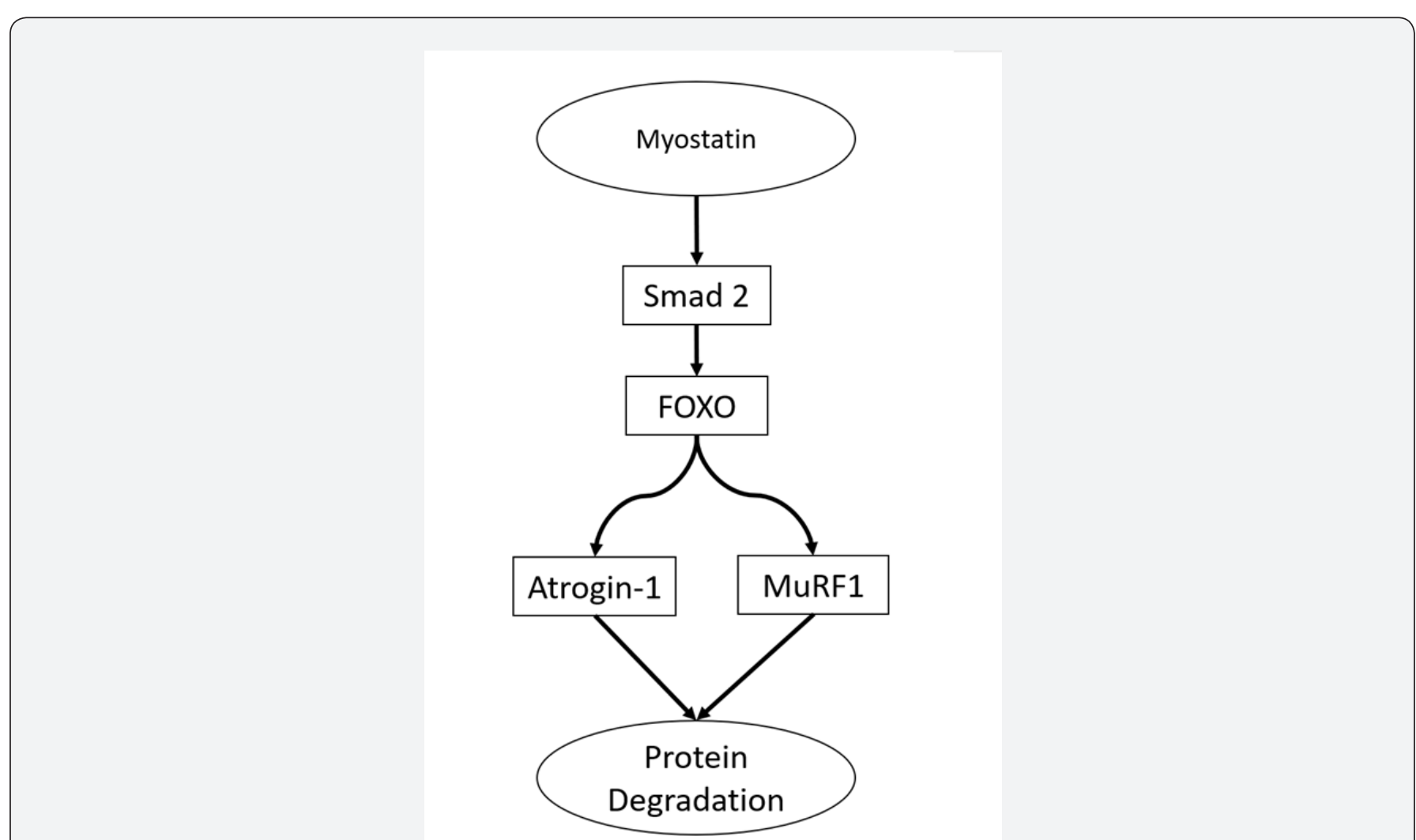

Figure 2: Schematic representation of the Myostatin pathway..

In fact, muscle hypertrophy produced by ACVR2B transfection can be inhibited by rapamycin and that induced by follistatin is blocked by inactivation in different segments of the IGF-1/ Akt/mTOR pathway $[9,21]$. Likewise, follistatin overexpression, induced by viral injection in skeletal muscle, increases Akt phosphorylation and signals the activation of protein synthesis, in a process dependent on mTOR activation and which is suppressed by exposure to rapamycin [7]. Apparently, inhibiting the interaction of SMAD3 with follistatin is critical for Akt-mTOR signaling even though, as demonstrated in other cell systems, SMAD3 is able to directly interact with Akt and suppress protein synthesis in that environment $[21,23]$.

Such evidence demonstrates that there is communication between the myostatin/activin-A complex and the IGF-1 signaling pathway in order to control the degree of muscle fiber hypertrophy [24]. However, it has been shown that other pathways are also involved in the skeletal muscle hypertrophy process. These include serum responsive factors (SRFs), which are required to induce hypertrophy in synergists' ablation models, in a role mediated by interleukins 6 and 4 (IL- 6 and IL- 4 ) which act in a paracrine manner to induce proliferation and satellite cell fusion $[25,26]$. It has also been shown that SRFs activate Akt through the microRNA, miR-486, which is shown to be able to inhibit PTEN phosphatase, which negatively affects PI3K-Akt signaling [27].

Androgens and beta- 2 adrenergic agonists are equally capable of activating the PI3K-Akt-mTOR pathway and contribute to increasing the protein synthesis process. In this sense, the administration of testosterone or mimetics that prioritize the development of male secondary sexual characteristics are capable of producing hypertrophy and animal models where there is a lack of testosterone, it reduces Igf- 1 mRNA, Akt phosphorylation and rate of protein synthesis in processes that are reversed with nandrolone [19]. Similarly, clenbuterol or formoterol, beta-2 adrenergic agonists, are able to activate, through the increase of cyclic AMP, Akt phosphorylation, in a process that is blocked by rapamycin [28].

Another extracellular protein known as Wnt7a is capable of contributing to hypertrophy through activation of satellite cells and binding to the Fzd7 receptor, which is also involved in the activation of the PI3K-Akt-mTOR pathway [29]. This process seems to be enhanced by the positive impact of tensional changes 
in the sarcolemma and membrane caveoli, which contain an abundance of the nitric oxide synthetase enzyme in its neuronal isoform, which is abundant in skeletal muscle. It is believed that the released nitric oxide would be able to interact with superoxide anions produced by the contractile fiber mitochondria during exercise, and promote the synthesis of peroxynitrite, an aggressive reactive oxygen species that, however, has already been involved in the activation of vanilloid receptors Trpv1 present in the sarcoplasmic reticulum, and subsequent release of calcium ions. Thus, the moderate increase in the concentration of calcium ions in the cytosol would be able to positively influence numerous metabolic aspects and also activate mTOR to promote alterations in the protein synthesis process $[14,19]$.

Mechanic stimuli in the membrane would also be able to activate mTOR through an Akt-independent pathway that involves the participation of phosphatidic acid and activated phospholipase $\mathrm{D}[7,30]$. On the other hand, the fourth isoform of the transcription factor PGC-alpha was recently identified, whose isoform 1 is traditionally involved in mitochondrial biogenesis and is targeted by AMPK. Differently, PGC $\alpha-4$ would be involved in increasing muscle mass and strength, being able to repress the action of myostatin and, in fact, in clenbuterol-induced hypertrophy it is abolished by deletion of the PGC $\alpha-4$ gene [16].

Finally, although we have previously discussed the role of satellite cells in the hypertrophy process, it should be noted that muscle regeneration recaptures embryonic and neonatal myogenesis in a process that involves the activation, self-renewal, proliferation and fusion of myogenic and near stem cells always includes immune activation and inflammation [31]. Anyway, it is important to emphasize that muscle hypertrophy may exist even in the absence of significant activation of satellite cells and in fact, when this phenomenon is stimulated by clenbuterol, the muscle growth process does not involve satellite cell activation, as occurs in reintroduction of gravitational load, after a period of intentional removal to induce muscle atrophy $[26,32]$.

Even in follistatin-induced hypertrophy signaling, satellite cells do not appear to play a role [15]. However, in the aforementioned experimental models, where synergists are intentionally removed from the limbs of animals to produce compensatory hypertrophy of the agonists, there is immediate proliferation and fusion of satellite cells, with well-evidenced increases in the number of myonuclei in a process that is also verified after eccentric contraction performed with high load and for a long time and capable of producing micro-lesions and localized inflammation [31]. Such experimental models are traditionally performed in rats and involve the removal of the gastrocnemius or tibialis anterior to observe, respectively, the hypertrophy of the soleus or extensor digitorum longus [33,34].

Likewise, it is well demonstrated that IGF-1-mediated hypertrophy involves the activation of satellite cells, and that the cytokines IL-6 and IL-4 are directly involved in muscle growth in experimental models involving overload [24]. Anyway, it is important to remember that even with the elimination of $90 \%$ of satellite cells through the use of toxins for PAX7, it is still possible to verify some muscular hypertrophy. It seems evident that, in mammals, there may be hypertrophy with or without the involvement of satellite cells $[15,18]$. In this context, acute and aggressive stimuli such as the elimination of synergists or intense exercise with a high eccentric component and presence of muscle damage, seem to necessarily involve the participation of satellite cells for regeneration and compensatory adaptive hypertrophy[35]. On the other hand, more gradual physical exercise stimuli and experimental models that replace the load on one or both limbs after intentional removal (functional overload model), the verified hypertrophy, does not seem to involve the activation of satellite cells, being exclusively associated to the increase of the protein synthesis process $[36,37]$.

\section{Conclusion}

Based on the above, we can verify the central, but antagonistic, roles of IGF-1 and myostatin in controlling muscle hypertrophy. The factors shown effect their actions through complex intracellular signaling mechanisms. In addition, other mechanisms contribute to the control of hypertrophy, such as amino acids, androgens and inflammatory molecules. Satellite cells are not always involved in hypertrophy, and there is an activation of them mediated or not by IGF-1 and other factors.

\section{References}

1. Hulmi JJ, Lockwood CM, Stout JR (2010) Effect of protein/essential amino acids and resistance training on skeletal muscle hypertrophy: A case for whey protein. Nutr Metab (Lond) 7(51): 1-11.

2. Trendelenburg AU, Meyer A, Rohner D, Boyle J, Hatakeyama S, et al (2009) Myostatin reduces Akt/TORC1/p70S6K signaling, inhibiting myoblast differentiation and myotube size. Am J Physiol Cell Physiol 296(6): C1258-C1270.

3. Arantes VHF, Silva DP, Alvarenga RL, Terra A, Koch AJ, et al (2020) Skeletal muscle hypertrophy: molecular and applied aspects of exercise physiology. German Journal of Exercise and Sport Research 50(2): 195-207.

4. Egerman MA, Glass DJ (2014) Signaling pathways controlling skeletal muscle mass. Crit Rev Biochem Mol Biol 49(1): 59-68.

5. Li S, Czubryt MP, McAnally J, Bassel-Duby R, Richardson JA, et al (2005) Requirement for serum response factor for skeletal muscle growth and maturation revealed by tissue-specific gene deletion in mice. Proc Natl Acad Sci U S A 102(4): 1082-1087.

6. Egan B, Zierath JR (2013) Exercise metabolism and the molecular regulation of skeletal muscle adaptation. Cell Metab 17(2): 162-84.

7. Shad BJ, Smeuninx B, Atherton PJ, Breen L (2015) The mechanistic and ergogenic effects of phosphatidic acid in skeletal muscle. Appl Physiol Nutr Metab 40(12): 1233-1241.

8. Clemmons DR (2009) Role of IGF-I in skeletal muscle mass maintenance. Trends Endocrinol Metab 20(7): 349-356.

9. Glass DJ (2010) PI3 kinase regulation of skeletal muscle hypertrophy and atrophy. Curr Top Microbiol Immunol 346: 267-278. 
10. Rodriguez J, Vernus B, Chelh I, Cassar-Malek I, Gabillard JC, et al. (2014) Myostatin and the skeletal muscle atrophy and hypertrophy signaling pathways. Cell Mol Life Sci 71(22): 4361-4371.

11. Goodman CA (2014) The role of mTORC1 in regulating protein synthesis and skeletal muscle mass in response to various mechanical stimuli. Rev Physiol Biochem Pharmacol 166: 43-95.

12. Philippou A, Barton ER (2014) Optimizing IGF-I for skeletal muscle therapeutics. Growth Horm IGF Res 24(5): 157-163.

13. Stokes T, Hector AJ, Morton RW, McGlory C, Phillips SM (2018) Recent Perspectives Regarding the Role of Dietary Protein for the Promotion of Muscle Hypertrophy with Resistance Exercise Training. Nutrients 10(2): 180 .

14. Ito N, Ruegg UT, Kudo A, Miyagoe-Suzuki Y, Takeda S (2013) Activation of calcium signaling through Trpv1 by nNOS and peroxynitrite as a key trigger of skeletal muscle hypertrophy. Nat med 19(1): 101-106.

15. Pallafacchina G, Blaauw B, Schiaffino S (2013) Role of satellite cells in muscle growth and maintenance of muscle mass. Nutr Metab Cardiovasc Dis 23(Suppl 1): S12-S18.

16. Ruas JL, White JP, Rao RR, Kleiner S, Brannan KT, et al (2012) A PGC1alpha isoform induced by resistance training regulates skeletal muscle hypertrophy. Cell 151(6): 1319-1331.

17. Stipanuk MH (2007) Leucine and Protein Synthesis: mTOR and Beyond. Nutr Rev 65(3): 122-129

18. Leite M, Machado M (2019) Signaling for Muscular Hypertrophy May Exist with or without Activation of Satellite Cell. Eur Academic Res 7(9): 4771-4789.

19. Vicencio JM, Estrada M, Galvis D, Bravo R, Contreras AE, et al (2011) Anabolic androgenic steroids and intracellular calcium signaling: a mini review on mechanisms and physiological implications. Mini Rev Med Chem 11(5): 390-398.

20. Chen PR, Lee K (2009) Invited Review: Inhibitors of myostatin as methods of enhancing muscle growth and development. J Anim Sci 94(8): 3125-3134.

21. Esser K (2008) Regulation of mTOR signaling in skeletal muscle hypertrophy. J Musculoskelet Neuronal Interact 8(4): 338-339.

22. Tsuchida K (2004) Activins, myostatin and related TGF-beta family members as novel therapeutic targets for endocrine, metabolic and immune disorders. Curr Drug Targets Immune Endocr Metabol Disord 4(2): 157-166.

23. Conery AR, Cao Y, Thompson EA, Townsend CM, Ko TC, et al. (2004) Akt interacts directly with Smad3 to regulate the sensitivity to TGF-beta induced apoptosis. Nat Cell Biol 6(4): 366-372.
24. Guerci A, Lahoute C, Hebrard S, Collard L, Graindorge D, et al. (2012) Srf-dependent paracrine signals produced by myofibers control satellite cell-mediated skeletal muscle hypertrophy. Cell Metab 15(1): 25-37.

25. Charvet C, Houbron C, Parlakian A, Giordani J, Lahoute C, et al. (2006) New role for serum response factor in postnatal skeletal muscle growth and regeneration via the interleukin 4 and insulin-like growth factor 1 pathways. Mol Cell Biol 26(17): 6664-6674.

26. Maltin CA, Delday MI (1992) Satellite cells in innervated and denervated muscles treated with clenbuterol. Muscle Nerve 15(8): 919-925.

27. Hitachi K, Tsuchida K (2013) Role of microRNAs in skeletal muscle hypertrophy. Frontiers in physiology 4(408): 1-7.

28. Berdeaux R, Stewart R (2012) cAMP signaling in skeletal muscle adaptation: hypertrophy, metabolism, and regeneration. Am J Physiol Endocrinol Metab 303(1): E1-17.

29. Schiaffino S, Dyar KA, Ciciliot S, Blaauw B, Sandri M (2013) Mechanisms regulating skeletal muscle growth and atrophy. FEBS J 280(17): 42944314.

30. Bond P (2017) Phosphatidic acid: biosynthesis, pharmacokinetics, mechanisms of action and effect on strength and body composition in resistance-trained individuals. Nutr Metab (Lond) 14(12): 1-9.

31. Costamagna D, Costelli P, Sampaolesi M, Penna F (2015) Role of Inflammation in Muscle Homeostasis and Myogenesis. Mediators Inflamm 2015: 805172.

32. Jackson JR, Mula J, Kirby TJ, Fry CS, Lee JD, et al. (2012) Satellite cell depletion does not inhibit adult skeletal muscle regrowth following unloading-induced atrophy. Am J Physiol Cell Physiol 303(8): C854-C861.

33. Huang S (2013) Inhibition of PI3K/Akt/mTOR signaling by natural products. Anticancer Agents Med Chem 13(7): 967-970.

34. Lee SJ (2004) Regulation of muscle mass by myostatin. Annu Rev Cell Dev Biol 20: 61-86.

35. Miyazaki M, Esser KA (2009) Cellular mechanisms regulating protein synthesis and skeletal muscle hypertrophy in animals. J Appl Physiol (1985) 106(4): 1367-1373.

36. Pasiakos SM (2012) Exercise and amino acid anabolic cell signaling and the regulation of skeletal muscle mass. Nutrients 4(7): 740-758.

37. Shaw RJ (2009) LKB1 and AMP-activated protein kinase control of mTOR signalling and growth. Acta Physiol (Oxf) 196(1): 65-80. 

$\begin{array}{ll}\text { (CC) } & \begin{array}{l}\text { This work is licensed under Creative } \\ \text { Commons Attribution 4.0 Licens } \\ \text { DOl: 10.19080/JETR.2021.06.555689 }\end{array}\end{array}$
Your next submission with Juniper Publishers will reach you the below assets

- Quality Editorial service

- Swift Peer Review

- Reprints availability

- E-prints Service

- Manuscript Podcast for convenient understanding

- Global attainment for your research

- Manuscript accessibility in different formats

( Pdf, E-pub, Full Text, Audio)

- Unceasing customer service

Track the below URL for one-step submission https://juniperpublishers.com/online-submission.php 